\title{
Article \\ Elastase-Activated Antimicrobial Peptide for a Safer Pulmonary Treatment of Cystic Fibrosis Infections
}

\author{
Margherita Degasperi ${ }^{1,2}$, Riccardo Sgarra ${ }^{1}$, Mario Mardirossian ${ }^{1}\left(\right.$, Sabrina Pacor ${ }^{1}\left(\mathbb{D}\right.$, Massimo Maschio $^{3}$ \\ and Marco Scocchi $1, *$ (D) \\ 1 Department of Life Sciences, University of Trieste, 34127 Trieste, Italy; \\ margherita.degasperi@areasciencepark.it (M.D.); rsgarra@units.it (R.S.); mmardirossian@units.it (M.M.); \\ pacorsab@units.it (S.P.) \\ 2 ARGO Open Lab Platform for Genome Sequencing, AREA Science Park, Padriciano, 34149 Trieste, Italy \\ 3 Institute for Maternal and Child Health, IRCCS Burlo Garofolo, 34134 Trieste, Italy; \\ massimo.maschio@burlo.trieste.it \\ * Correspondence: mscocchi@units.it
}

Citation: Degasperi, M.; Sgarra, R.; Mardirossian, M.; Pacor, S.; Maschio, M.; Scocchi, M. Elastase-Activated Antimicrobial Peptide for a Safer Pulmonary Treatment of Cystic Fibrosis Infections. Antibiotics 2022, 11, 319. https://doi.org/10.3390/ antibiotics11030319

Academic Editor: Jean-Marc Sabatie

Received: 31 December 2021

Accepted: 25 February 2022

Published: 28 February 2022

Publisher's Note: MDPI stays neutral with regard to jurisdictional claims in published maps and institutional affiliations.

Copyright: (C) 2022 by the authors. Licensee MDPI, Basel, Switzerland. This article is an open access article distributed under the terms and conditions of the Creative Commons Attribution (CC BY) license (https:// creativecommons.org/licenses/by/ $4.0 /)$.

\begin{abstract}
As bioactive small proteins with antimicrobial and immunomodulatory activities that are naturally produced by all living organisms, antimicrobial peptides (AMPs) have a marked potential as next-generation antibiotics. However, their development as antibacterial agents is limited by low stability and cytotoxicity. D-BMAP18, a membrane-permeabilizing antimicrobial peptide composed of D-amino acids, has shown good antibacterial and anti-inflammatory activities but also a nonnegligible cytotoxicity against eukaryotic cell lines. In this study, a prodrug has been developed that extends the peptide with a negatively charged, inactivating sequence containing the cleavage site for neutrophil elastase (NE). The ultimate goal was to allow the activation of D-BMAP18 by endogenous elastase only at the site of infection/inflammation, enabling a slow and targeted release of the pharmacologically active peptide. In vitro activation of Pro-D-BMAP18 was confirmed using purified NE. Its antimicrobial and cytotoxic activities were tested in the presence and absence of elastase and compared to those of the parental form. The prodrug had minimal activity in the absence of elastase, while its proteolysis product retained an appreciable antimicrobial activity but lower cytotoxicity. Moreover, Pro-D-BMAP18 was found to be correctly converted to D-BMAP18 in the presence of CF sputum as a model of the lung environment and showed good antimicrobial activity under these conditions.
\end{abstract}

Keywords: antimicrobial peptide; cystic fibrosis; pro-drug; elastase; Pseudomonas aeruginosa

\section{Introduction}

The morbidity and mortality of cystic fibrosis patients (CF) is mostly caused by respiratory failure due to chronic lung infections [1]. Intensive antibiotic therapy for bacterial lung infections contributes to the development of multidrug-resistant (MDR) pathogens [2]. In addition, the spread of pathogens in the form of biofilm communities, which are naturally resistant to many antibiotics, makes it difficult to eradicate infections [3,4]. Pseudomonas aeruginosa is the most commonly described opportunistic pathogen affecting CF patients [5]. In addition, several studies have reported that lung function declines more rapidly in patients chronically coinfected with Candida spp. and P. aeruginosa [6].

Antimicrobial resistance requires the development of novel antimicrobial agents effective against multidrug-resistant strains to complement or replace current antibiotic therapies. In this scenario, antimicrobial peptides (AMPs) are interesting molecules due to their broad spectrum of activity against MDR strains [7-9]. Antimicrobial peptides (AMPs) are key components of the innate immune system of vertebrates and invertebrates, where they exert multiple functions, including direct antimicrobial activity and immunomodulatory activities that stimulate the immune system and suppress the inflammatory response [9-13]. 
The killing mechanism of AMPs is mainly based on permeabilization of the microbial membrane [11,14], although other mechanisms based on multiple molecular targets may accompany or replace membrane permeabilization [15]. AMPs have often demonstrated the ability to circumvent common microbial resistance mechanisms to antibiotics [10], a property likely related to their multiple killing mechanisms and lack of unique molecular targets [11,12] and to their synergistic activity between AMPs and antibiotics [16].

The therapeutic potential of various AMPs against CF isolates has been widely reported [17-20]. Some of them, the cathelicidins, have also been tested against CF isolates [21,22] and shown potent broad-spectrum antimicrobial activity in vitro against Grampositive and Gram-negative bacteria and fungi, although they were quite cytotoxic to human erythrocytes and neutrophils at higher concentrations relative to microbicidal ones [23]. A truncated form of cathelicidin BMAP-27, termed BMAP-18, which lacks nine C-terminal hydrophobic residues, showed antimicrobial activity against the planktonic form of $P$. aeruginosa CF isolates [24], with efficacy comparable to tobramycin and in some cases even higher $[22,24]$. Unfortunately, the peptide was ineffective against acute lung infections in mice, probably because of its rapid degradation [24]. Its enantiomeric form, D-BMAP18, showed non-negligible cytotoxicity against different cell lines [25,26] despite its high antibacterial and anti-inflammatory properties also in the presence of CF sputum [25].

A prodrug approach has been used previously to reduce toxicity and increase specificity through selective activation [27]. Forde and colleagues designed several AMP prodrugs such that their net positive charge was masked by a negative pro-moiety containing a substrate for the enzyme neutrophil elastase (NE). These prodrugs of AMPs limited the cytotoxic effects of AMP treatment and made antimicrobial activity dependent on the host enzyme NE. The pro-AMP modification reduced host toxicity in a mouse model of lung administration, with the pro-peptide being less toxic than the active peptide [28]. However, the results depended on the type of peptide used, and there is still considerable scope for improving the selectivity of pro-AMPs [28].

Mammals produce cathelicidins as inactive proforms which are processed by NE to obtain active peptides $[29,30]$. The aim of this study was to reproduce this activation process by designing a BMAP-18 proform that is activated by NE only at the site of infection/inflammation, reducing its residual cytotoxicity. Pro-D-BMAP18 was synthesized, its proteolytic activation was tested, and its antimicrobial activity and cytotoxicity before and after proteolytic activation were investigated. The results provided new insights into the biocompatibility of AMPs for the treatment of lung infections in CF.

\section{Results}

\subsection{Design of the Pro-Peptide Pro-D-BMAP18 Activated by the Proteases in the Site of Infection}

To obtain a stable inactive form of D-BMAP18 that releases the active peptide at the site of infection by specific proteolysis, a pro-drug peptide was designed and synthesized. This peptide was designed with a short, negatively charged N-terminal pro-region linked to a cationic C-terminal part corresponding to the D-BMAP18 peptide. The chimeric peptide contained a cleavage site for elastase between the two parts to allow the release of the active D-BMAP18. The C-terminus and the N-terminus of the pro-peptide were amidated and acetylated, respectively, to remove any negative charge in the active C-terminal peptide and any positive charge in the N-terminal pro-form (Figure 1). In this way, the endogenous elastase present at the site of infection/inflammation might be able to process the propeptide in situ and minimize its cytotoxicity.

\section{$\begin{array}{ll}\text { Elastase }-{ }^{V} \text { SQLEEGEGEE-NHAc } & \boldsymbol{G}_{\boldsymbol{R} \boldsymbol{F} \boldsymbol{K} \boldsymbol{R} \boldsymbol{F} \boldsymbol{K} \boldsymbol{K} \boldsymbol{F} \boldsymbol{K} \boldsymbol{K} \boldsymbol{L} \boldsymbol{F} \boldsymbol{K} \boldsymbol{L} \boldsymbol{S}-\mathrm{CONH}_{2}}\end{array}$}

Figure 1. Scheme and sequence of Pro-D-BMAP18. The mature D-peptide released upon cleavage is shown in italics and bold. The line represents the neutrophil elastase cleavage site. The turn encompassing Val11 and Gly12 was predicted using the PepFold3 tool. 


\subsection{Antimicrobial Activity of Pro-D-BMAP18 against Bacterial and Fungal Strains}

To determine whether the pro-sequence of Pro-D-BMAP18 effectively sequesters the active peptide impairing its activity, the antimicrobial activity of Pro-D-BMAP18 and DBMAP18 were tested against 12 different $P$. aeruginosa isolates from CF patients which have been previously characterized [22]. The Pro-D-BMAP18 displayed a dramatic decrease (4-32 fold) of its antimicrobial activity compared to free D-BMAP18, confirming that the pro-sequence efficiently impaired the antimicrobial activity of D-BMAP18 (Table 1).

Table 1. MIC ( $\mu \mathrm{g} / \mathrm{mL})$ values of D-BMAP18 vs. Pro-D-BMAP18 against P. aeruginosa strains.

\begin{tabular}{ccc}
\hline Strains & Pro-D-BMAP18 & D-BMAP18 \\
\hline PAO1 & 128 & 4 \\
RP 73 & 128 & 4 \\
PA 03 & 128 & 8 \\
PA 05 & 32 & 4 \\
PA07 & 64 & 8 \\
PA08 & 128 & 8 \\
PA 09 & 64 & 4 \\
PA 10 & 64 & 8 \\
PA 14 & 64 & 16 \\
PA 21 & 128 & 16 \\
PA 22 & 16 & 4 \\
PA 31 & 128 & 16 \\
\hline
\end{tabular}

\subsection{Proteolytic Activation of Pro-D-BMAP18}

To assess whether the pro-peptide could release the active D-BMAP18 after elastase digestion, cleavage of Pro-D-BMAP18 was evaluated in vitro by incubating the pro-drug with neutrophil elastase (NE). After $1 \mathrm{~h}$ incubation, $50 \%$ of the prodrug was cleaved, and the cleavage was complete after $4 \mathrm{~h}$ incubation. Mass spectrometry analysis after cleavage identified only D-BMAP18 ( $\mathrm{Mw}=2342)$. No other products were detected, demonstrating the specificity of the cleavage and that no other unwanted molecules were released during proteolysis (Figure S1).

2.4. Antimicrobial Activity of Pro-D-BMAP18 in the Presence of Elastase and in the Supernatant of HL-60 Cells

The antimicrobial activity of the peptide released from the pro-drug by proteolysis was evaluated by MIC assays, in which the Pro-D-BMAP18 was incubated with two different strains of P. aeruginosa (PAO1 and RP37) and two strains of C. albicans (ATCC 90029 and SC $5314)$ in the presence of NE.

Recovery of antibacterial activity of the released D-BMAP18 was clear but incomplete compared to free D-BMAP18. The released peptide recovered its full antimicrobial activity only after the addition of $300 \mathrm{mM} \mathrm{NaCl}$ to the medium (final concentration $=450 \mathrm{mM}$ ) (Table 2). The activity of cleaved Pro-D-BMAP18 was also evaluated against the synthesis of new biofilm at sub-MIC concentrations and against preformed biofilm. The pro-peptide incubated in the presence of NE inhibited the formation of new biofilm with activity comparable to the parental form (Figure S2).

The release of the active D-BMAP18 moiety was also evaluated by incubating the ProD-BAMP18 with the exhausted medium of degranulated neutrophil-like cells which had been differentiated from HL-60 cells and therefore enriched in proteases. Pro-D-BMAP18 was incubated for various times with this conditioned medium and each sample was used to perform an MIC assay against $P$. aeruginosa cells. The results showed a time dependent conversion of the pro-peptide to D-BMAP18, suggesting that neutrophils released sufficient amount of elastase to process Pro-D-BMAP18 into D-BMAP18 (Table 2). 
Table 2. MIC values $(\mu \mathrm{g} / \mathrm{mL})$ of D-BMAP18 and of D-BMAP18 released from Pro-D-BMAP18 incubated with elastase or elastase-containing conditioned cell medium.

\begin{tabular}{|c|c|c|c|c|}
\hline \multirow[t]{2}{*}{ Compound } & \multicolumn{2}{|c|}{ P. aeruginosa } & \multicolumn{2}{|c|}{ C. albicans } \\
\hline & PAO1 & RP73 & ATCC 90029 & SC5314 \\
\hline D-BMAP18 & 16 & 8 & 2 & 16 \\
\hline Pro-D-BMAP18 & 128 & 128 & 16 & $>128$ \\
\hline Pro-D-BMAP18 + NE & 32 & 32 & 4 & 32 \\
\hline Neutrophil elastase (NE) & $>128$ & $>128$ & $>128$ & $>128$ \\
\hline Pro-D-BMAP18 + NE + $350 \mathrm{mM} \mathrm{NaCl}$ & 16 & 8 & 2 & 16 \\
\hline Pro-D-BMAP18 + cell supernatant, 4 h & 64 & 64 & nd & nd \\
\hline Pro-D-BMAP18 + cell supernatant, $18 \mathrm{~h}$ & 32 & 32 & nd & nd \\
\hline Pro-D-BMAP18 + cell supernatant, 24 h & 32 & 32 & nd & nd \\
\hline
\end{tabular}

The results are the mode of three independent experiments performed in duplicate. nd: not determined.

\subsection{Biocompatibility of the Pro-D-BMAP18 in the Presence of Elastase}

To evaluate its biocompatibility, Pro-D-BMAP18 and human NE were incubated with the adenocarcinomic human alveolar basal epithelial cells A-549 or chronic lymphocytic leukaemia cells MEC-1 for $24 \mathrm{~h}$. Free D-BMAP18 was used in parallel as a comparison. Compared with the untreated control, $50 \mu \mathrm{g} / \mathrm{mL}$ Pro-D-BMAP18 in the presence of elastase decreased the viability of A- 549 cells by $20 \%$. A similar result was observed in the absence of elastase. In contrast, D-BMAP18 at the same concentration reduced viability by $60 \%$ (Figure 2).

Treatment of MEC-1 cells with Pro-D-BMAP18 and NE at a concentration of $50 \mu \mathrm{g} / \mathrm{mL}$ reduced cell viability by less than $30 \%$ compared with the untreated control, whereas D-BMAP18 at the same concentration reduced cell viability by $70 \%$ compared with the same control. A higher viability for NE-treated Pro-D-BMAP18 than for D-BMAP18 was also observed at $25 \mu \mathrm{g} / \mathrm{mL}$ (Figure 2).

A)

A-549

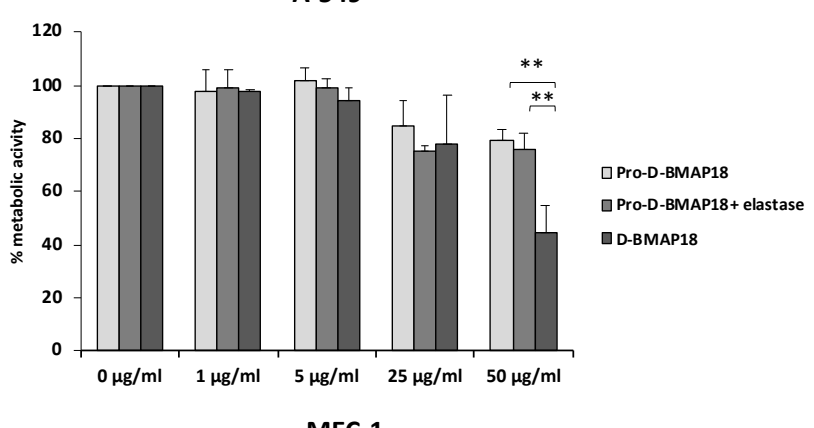

B)

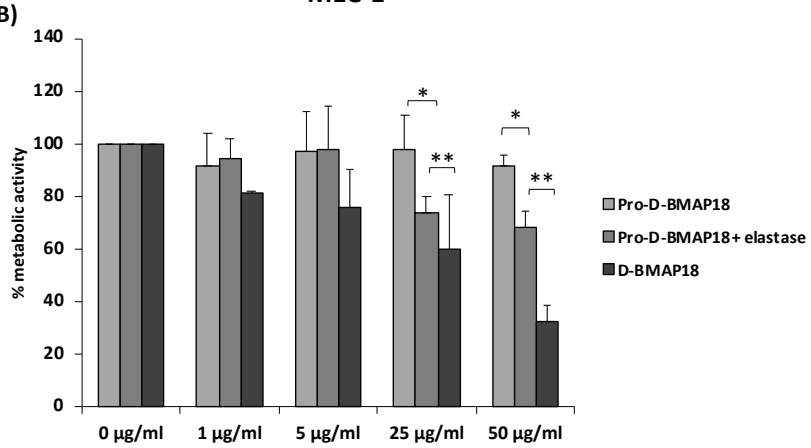

Figure 2. Cell viability assay in the presence of NE-activated Pro-D-BMAP18. An MTT assay was performed using (A) adenocarcinomic human alveolar basal epithelial cells A-549 and (B) B-chronic lymphocytic leukaemia cells MEC-1. The percentages shown are of metabolically active cells compared with untreated controls after $24 \mathrm{~h}$ incubation with different concentrations of Pro-D-BMAP18 with or without NE and D-BMAP18. Results of three different experiments in internal triplicate $(\mathrm{n}=9)$. ${ }^{*}=p<0.05 ;{ }^{* *}=p<0.01$. A Student's $\mathrm{n}=$ of the treatments vs. the untreated control is reported. 
Overall, these data indicate very low cytotoxicity for Pro-D-BMAP18, which increased weakly in the presence of elastase and remained lower than that for D-BMAP18, suggesting that gradual activation of the pro-form within $24 \mathrm{~h}$ leads to a significant reduction in cytotoxicity.

\subsection{Antimicrobial Activity of Pro-D-BMAP18 in CF Sputum against P. aeruginosa RP73 or C. albicans SC 5314}

Finally, the antimicrobial activity of Pro-D-BMAP18 was tested in CF sputum. It was investigated whether the proteolytic activity of endogenous elastase in CF sputum was sufficient to process Pro-D-BMAP18 and unmask its antibacterial activity. The number of viable CFUs of the P. aeruginosa strain RP73 and C. albicans strain SC5314 was determined by incubating the pathogens with Pro-D-BMAP18 in 25\% $(v / v)$ CF sputum diluted in SCFM with $300 \mathrm{mM} \mathrm{NaCl}$ added, a medium that mimics the chemical composition of CF sputum [22]. Pro-D-BMAP18 acquired antimicrobial activity in CF sputum. After $4 \mathrm{~h}$ incubation the bactericidal efficacy of Pro-D-BMAP18 was comparable to that of the D-BMAP18, displaying a 2-log reduction of viable P. aeruginosa RP73 cells and an approximately 1-log reduction of C. albicans cells (Figure 3). When the pro-drug was incubated with CF sputum samples that had been heat-inactivated to kill any enzymatic activity, the peptide did not recover its antimicrobial activity. This confirmed the role of the elastase (or other unspecified proteolytic enzymes in CF sputum) in cleaving Pro-D-BMAP18 to its active form, D-BMAP18. Thus, the sputum from CF patients contained sufficient active proteases (elastase) to convert the Pro-D-BMAP18 into a compound (D-BMAP18), exerting antimicrobial activity under the physio(patho)logical conditions of CF lungs.
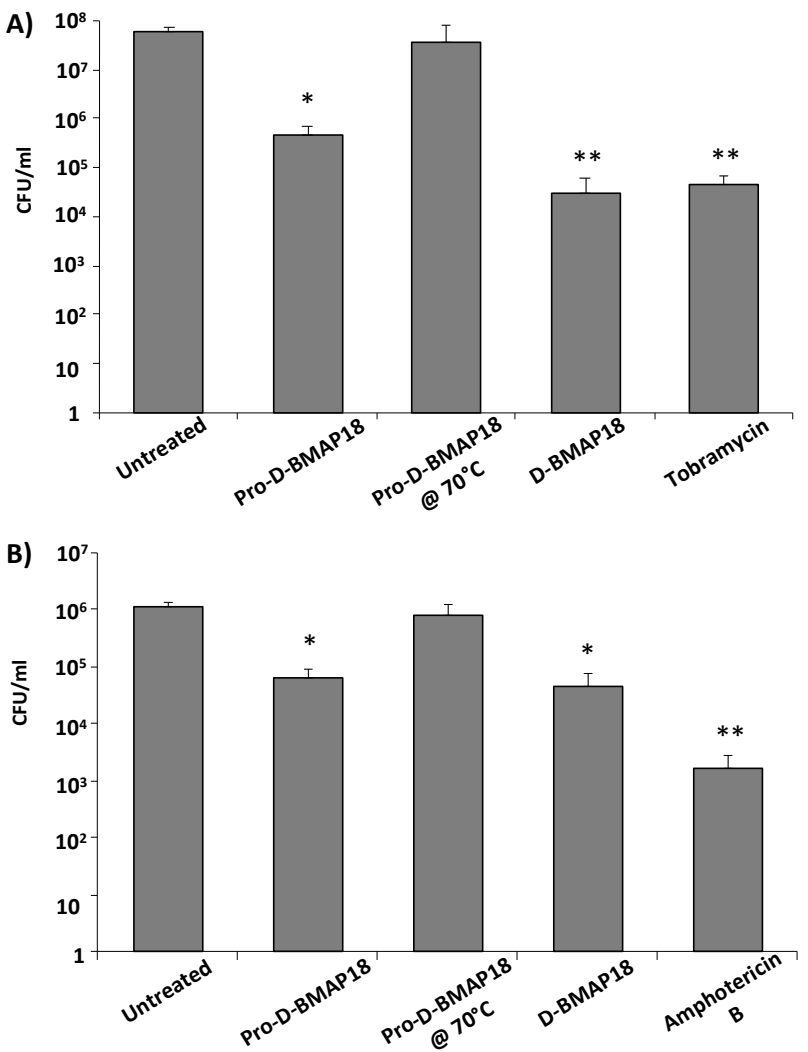

Figure 3. Antimicrobial activity of Pro-D-BMAP18 in 25\% (v/v) CF sputum in SCFM $+300 \mathrm{mM}$ $\mathrm{NaCl}$. CFU/mL count of (A) P. aeruginosa RP73 and (B) C. albicans SC5314 after $4 \mathrm{~h}$ incubation with Pro-D-BMAP18 $(64 \mu \mathrm{g} / \mathrm{mL}), \mathrm{D}-\mathrm{BMAP} 18(64 \mu \mathrm{g} / \mathrm{mL})$, tobramycin $(8 \mu \mathrm{g} / \mathrm{mL})$, and amphotericin B $(1 \mu \mathrm{g} / \mathrm{mL})$. Pro-D-BMAP18 $(64 \mu \mathrm{g} / \mathrm{mL})$ in heat-inactivated sputum was used as a negative control for enzymatic activity. Results are from three separate experiments in internal duplicate $(n=6)$. ${ }^{*}=p<0.05 ;{ }^{* *}=p<0.01$. A Student's $t$-test of the treatments vs the untreated control is indicated. 


\section{Discussion}

Pro-D-BMAP18, an inactive form of D-BMAP18, was developed as a safer antimicrobial compound for the treatment of lung infections. This involved modifications that have been used for other antibacterial agents [27,31,32]. Neutrophils represent the major cell population among the inflammatory cells recruited to the airways of CF patients, where they are responsible for the in situ release of elastase [33]. For this reason, Pro-D-BMAP18 was developed by adding an inactivating extra sequence to the N-terminus of D-BMAP18, which contains the cleavage site for elastase. The presence of this specific cleavage site should allow the gradual release of the active antimicrobial peptide only in environments enriched with NE, such as the inflamed and infected CF lung. This rationale had already been used by Forde and colleagues $[20,27]$ to convert other antimicrobial peptides into safer pro-drugs in both in vitro and in vivo experiments [20]. Differently to them, we designed the pro-drug using an optimized cathelicidin as the active antimicrobial component and we introduced the native cleavage site for elastases present in the cathelicidin sequence to exploit this property.

The pro-sequence successfully blocked the peptide and prevented its antimicrobial effect as well as its undesirable cytotoxicity toward eukaryotic cells. The pro-peptide was then correctly converted into D-BMAP18 by elastase, demonstrating that Pro-D-BMAP18 was activated only under the conditions for which it was designed. However, the electrostatic interaction between the anionic pro-sequence and the cationic active peptide probably kept the two moieties bound to each other in part of the molecular population even after cleavage. This eroded some of the antimicrobial activity of the pro-drug compared with native D-BMAP18, as the released peptide fully recovered its antimicrobial activity only in the presence of $450 \mathrm{mM} \mathrm{NaCl}$ when tested in $\mathrm{CF}$ mucus against both bacterial and fungal strains. Most likely, the addition of salts also displaces the remaining pro-sequences from active D-BMAP18, unmasking its full antimicrobial activity, and might help to avoid excessive interaction with mucus. However, the presence of $\mathrm{NaCl}$ does not represent a major problem for potential therapeutic applications of Pro-D-BMAP18, as the compound per se shows high antimicrobial activity both in the presence and absence of high $\mathrm{NaCl}$ concentrations. In contrast, our data raise the interesting possibility of combining the use of Pro-D-BMAP18 with sodium chloride. Aerosol administration of hypertonic $\mathrm{NaCl}$ solutions is already used to treat CF patients to soften mucus [34]. Therefore, Pro-D-BMAP18 could be administered in these treatments not only without interference but even with enhancement of its antimicrobial activity.

To be sure that Pro-D-BMAP18 can be used under the really difficult conditions of CF sputum, we demonstrated that the number of neutrophil elastases or other proteolytic enzymes present in this CF sputum was sufficient to convert Pro-D-BMAP18 to D-BMAP18 within a few hours. This was previously observed by Forde and colleagues [27], but we have expanded the group of pathogens tested to include $C$. albicans, which frequently co-infects the lungs of CF patients. In contrast to Forde, who reported a $20 \%$ reduction in bacterial load after pro-drug treatment in CF human bronchoalveolar lavage, we observed a 2-log reduction by treatment with Pro-D-BMAP18 activated in diluted CF sputum. Thus, the in situ release of D-BMAP18 from the pro-drug could proceed correctly in the lungs of patients thanks to the endogenous enzymes that are always present in inflamed lungs [35].

Interestingly, activated pro-D-BMAP18 has a much smaller effect on human cell lines in vitro than D-BMAP18. This suggests that the slow elastase-dependent release of DBMAP18 from Pro-D-BMAP18 reduces the deleterious effects of administering high doses of active peptides to host cells. It is therefore tempting to also assume a higher in vivo biocompatibility of Pro-D-BMAP18 compared to D-BMAP18, which has shown significant side effects both in cell cultures and in vivo [26]. Further experiments in this direction are planned. The demonstrated improvement in biocompatibility of Pro-D-BMAP18, at least in vitro, is relevant to the scenario of the clinical application of AMPs, since one of the most common side effects of AMPs is acute toxicity in vitro and in vivo [36,37]. All these observations confirmed that in situ activation of Pro-D-BMAP18 can overcome the 
side effects of D-BMAP18 and that it exhibits lower in vitro cytotoxicity and retains the antimicrobial properties of the parental form. These results will direct evaluation of the in vivo effects of the pro-drug to determine whether it can be introduced into the lungs of infected animals. Peptide antibacterial pro-drugs were recently administered into the lungs using a vibrating mesh nebulizer, suggesting that the pro-drug modification is not harmful [20] and supporting further development of pro-AMPs as therapeutics in CF.

In conclusion, to date, more than 3000 AMPs have been discovered, but only seven of them have been approved by the FDA due to issues related to stability and/or toxicity [37]. We have shown that the addition of a specific, inactivating extra sequence to an antimicrobial D-peptide could be a promising solution for the specific in situ activation of AMPs. By adding a negatively charged extra sequence to D-BMAP18, we could obtain a safe Pro-D-BMAP18 peptide that retains the antimicrobial activity of the parental form but has higher biocompatibility towards human cells. This type of formulation could be easily applied to other cathelicidins and could be a promising solution for the in vivo clinical application of antimicrobial peptides.

\section{Materials and Methods}

\subsection{Bacterial and Fungal Strains}

Previously characterized Pseudomonas aeruginosa strains, isolated from CF patients, were used. Each CF isolate was resistant to at least three of the following groups of antibiotics: $\beta$-lactams with or without $\beta$-lactamase inhibitor, aminoglycosides, fluoroquinolones, folate-pathway inhibitors (trimethoprim-sulphamethoxazole), tetracyclines, and macrolides. P. aeruginosa RP73, and P. aeruginosa PAO1 were used as reference strains [21,22]. All strains were stored at $-80{ }^{\circ} \mathrm{C}$ until use and plated on Mueller-Hinton agar (MHA; Oxoid S.p.A., Milan, Italy). The Candida albicans strains used were ATCC 90029 and SC 5314. All strains were stored at $-80{ }^{\circ} \mathrm{C}$ until used and plated on Sabouraud agar (Sigma-Aldirch, MO, USA).

\subsection{Antimicrobial Compounds and Synthesis of Pro-D-BMAP18}

D-BMAP18 (GRFKRFRKKFKKLFKKLS-am) ( $\geq 95 \%$ purity) was purchased from NovoPro Bioscience Inc. (Shangai, China), freeze-dried three times from $\mathrm{HCl} 10 \mathrm{mM}$ to remove residual TFA (CT60e Heto, Technology of Scandinavia) and finally resuspended in sterile $\mathrm{H}_{2} \mathrm{O}$. Tobramycin was purchased from Sigma-Aldrich (St. Louis, MO, USA) and resuspended in $\mathrm{H}_{2} \mathrm{O}$ at a final concentration of $5 \mathrm{mg} / \mathrm{mL}$. Amphotericin $\mathrm{b}$ was purchased from Sigma-Aldrich (St. Louis, MO, USA) and resuspended in $\mathrm{H}_{2} \mathrm{O}$ at a final concentration of 10 $\mathrm{mg} / \mathrm{mL}$. All peptides and antibiotics were stored at $-20^{\circ} \mathrm{C}$.

Pro-D-BMAP18 (Ac-EEGEGEELQSVGRFKRFRKKFKKLFKKLS-am; D-residues are reported in bold and italics) was synthesized according to Mardirossian and colleagues [26]. Before cleaving the pro-peptide from the resin, its N-terminus was acetylated incubating the resin for $5 \mathrm{~min}$ in $20 \%(\mathrm{v} / \mathrm{v})$ acetic anhydride in dimethylformamide at room temperature. Subsequently, 1.5 equivalent of N,N-Diisopropylethylamine (DIPEA) was added to the solution, prolonging the incubation for another $30 \mathrm{~min}$. The resin was then washed twice with dimethylformamide, dichloromethane, and methanol. The efficiency of the acetylation reaction was checked using a Keiser test kit (Sigma-Aldrich), according to the instructions of the supplier. All of these reagents were purchased from Sigma-Aldrich. The peptide was then cleaved from the resin as reported in [26], lyophilized three times with $10 \mathrm{mM}$ $\mathrm{HCl}$ (CT60e Heto, Technology of Scandinavia) to remove residual TFA, and resuspended in sterile $\mathrm{H}_{2} \mathrm{O}$.

The concentration of the stock solution of peptides was evaluated by spectrophotometric determination of peptide bonds $\left(\varepsilon_{214 \mathrm{~nm}}\right)$ according to Kuipers and Gruppen, with slight modifications [38]. 


\subsection{Cleavage of Pro-D-BMAP18 by Human Elastase in HEPES and by HL-60 Cells}

Pro-D-BMAP18 (500 ng) was mixed with human neutrophil elastase (Human Neutrophil Elastase, Abcam, Cambridge, UK) at a molar ratio of 100:1, respectively, and incubated at $37^{\circ} \mathrm{C}$ in $50 \mu \mathrm{L}$ HEPES $100 \mathrm{mM}$ pH 7.0. Then, $15 \mu \mathrm{L}$ of the mixture were withdrawn at different time points, the reaction was stopped by dilution in $15 \mu \mathrm{L}$ of ice-cold $\mathrm{H}_{2} \mathrm{O}+$ $0.1 \%(v / v)$ TFA and frozen at $-20^{\circ} \mathrm{C}$ until HPLC-MS analysis. Each sample was analysed by HPLC using the analytic column Symmetry ${ }^{\circledR} \mathrm{C} 18(100 \AA$, $3 \mu \mathrm{m}, 3 \mathrm{~mm} \times 100 \mathrm{~mm}$; Waters, Billerica, MA, USA). The elution was performed by a linear gradient of solvent $\mathrm{B}(0.05 \%$ $v / v$ TFA in AcCN) in A $(0.05 \% v / v$ TFA in water) from the $20 \%(v / v)$ to the $35 \%(v / v)$ of $\mathrm{B}$ in $15^{\prime}$ under a flow rate of about $15 \mu \mathrm{L} / \mathrm{min}$. The HPLC was connected to the mass analyser HCT ultra (Bruker Daltonics, Billerica, MA, USA) equipped with an electrospray ionization (ESI-MS) system and using a capillary voltage of $200 \mathrm{~V}$.

\subsection{Preparation of Conditioned Medium from Neutrophil-like Cells}

The promyelocytic human cells HL-60 (ATCC CCL-240 ${ }^{\mathrm{TM}}$ ) were grown in RPMI medium (Sigma-Aldrich, St. Louis, MO, USA) supplemented with 20\% $(v / v)$ fetal bovine serum (FBS, EuroClone, Milan, Italy), $100 \mathrm{U} / \mathrm{mL}$ penicillin/streptomycin (Sigma-Aldrich, MO, USA) and $2 \mathrm{mM}$ L-glutamine (EuroClone, Milan, Italy) at $37{ }^{\circ} \mathrm{C}$ in $5 \% \mathrm{CO}_{2}$ in 96 -well U-bottom microtiter plates (Sarstedt, Milan, Italy). Differentiation to neutrophil-like cells was induced by culturing the cells in the presence of $100 \mathrm{nM}$ phorbol myristate acetate (PMA, Sigma-Aldrich, St. Louis, MO, USA) for 6 days [39]. Differentiation was assessed by cell cycle analysis. Then, $10^{6}$ cells were fixed in $1 \mathrm{~mL}$ ethanol and washed twice using $1 \mathrm{~mL}$ PBS (Sigma-Aldrich, MO, USA, $\mathrm{pH}=7.4$ ) for $5 \mathrm{~min}$ at $500 \times \mathrm{g}$. Cells were stained with a solution of $1 \%(v / v)$ propidium iodide (PI; Sigma-Aldrich, St. Louis, MO, USA, $1 \times)$, 0.5\% (v/v) FITC (Sigma-Aldrich, MO, USA), and 0.4\% $(v / v)$ RNasi A (Sigma-Aldrich, MO, USA) in PBS. After overnight incubation at $4{ }^{\circ} \mathrm{C}$, cells were analysed by the cytofluorimeter Cytomics FC 500 (Beckman-Coulter, Inc., Fullerton, CA, USA). To induce the release of elastase by the differentiated HL-60 cells, after 6 days of incubation, the exhausted medium was discarded and $1 \mathrm{~mL}$ of fresh medium containing $100 \mu \mathrm{M}$ PMA (Sigma-Aldrich, St. Louis, MO, USA) was added to the wells for $2 \mathrm{~h}$. The medium and the cells were collected and centrifuged at $300 \times g$ for $10 \mathrm{~min}$. The supernatant was collected for further assays.

\subsection{Evaluation of Antimicrobial Activity}

The antibacterial activity of the peptides was evaluated as MIC (minimum inhibitory concentration) in both the MH and supernatant of HL-60 cells. Two-fold serial dilutions of Pro-D-BMAP18 $(128 \mu \mathrm{g} / \mathrm{mL})$ in the presence of elastase $(12.8 \mu \mathrm{g} / \mathrm{mL})$ at 100:1 molar ratio and D-BMAP18 were prepared in MH medium in 96-well U-bottom microtiter plates (Sarstedt, Milan, Italy) following the EUCAST guidelines. Briefly, serial two-fold dilutions of the compounds were prepared in the medium and aliquoted in round-bottom 96-well microtiter plates (Sarstedt). Each well was inoculated with a standardized inoculum, grown overnight, then re-grown in new medium to optical density at $600 \mathrm{~nm} \approx 0.3$, and diluted to achieve a final test concentration of about $2.5 \times 10^{5} \mathrm{CFU} / \mathrm{mL}$. The MIC was measured as the lowest concentration of the peptide that completely inhibited visible bacterial growth after incubation at $37^{\circ} \mathrm{C}$ for $24 \mathrm{~h}$.

Concerning the antimicrobial activity in the exhausted medium of differentiated HL-60 cells, Pro-D-BMAP18 (final concentration: $128 \mu \mathrm{g} / \mathrm{mL}$ ) was incubated in the supernatant for $4 \mathrm{~h}, 18 \mathrm{~h}$ and $24 \mathrm{~h}$. For each time-point, $100 \mu \mathrm{L}$ of the medium containing the pro-peptide was taken and used for an MIC assay against the P. aeruginosa strains PA01 and RP73, as reported above.

The antifungal activity (MIC) against both the C. albicans strains ATCC90029 and SC 5314 was tested in Sabouraud broth (Sigma-Aldirch, MO, USA) according to the guidelines of the National Committee for Clinical Laboratory Standards. Fungal colonies were resuspended in $5 \mathrm{~mL}$ sterile PBS and the optical density (OD) was measured at $600 \mathrm{~nm}$ (Ultraspec 2100 pro, Amersham Bioscience, Buckinghamshire, UK). Each well was in- 
oculated with a standardized inoculum of $50 \mu \mathrm{L}$ to achieve a final test concentration of $5 \times 10^{4} \mathrm{CFU} / \mathrm{mL}$. After incubation of the plate at $30{ }^{\circ} \mathrm{C}$ for $48 \mathrm{~h}$, MIC was determined as the lowest concentration of antimicrobial peptide resulting in the complete inhibition of visible growth.

The biofilm eradication protocol (see Figure S1) was performed according to [22] for the cultivation of bacterial and biofilm and using the protocol described in [22] for its staining with MTT.

\subsection{In Vitro Cytoxicity Assays}

Cytotoxicity was evaluated as cell viability by the MTT assay using two different human cells lines: the adenocarcinomatous human alveolar basal epithelial cells A-549 and the human lymphoid MEC-1 cells (DSMZ, ACC 497). A-549 and MEC-1 cells grew in Dulbecco's MEM (Sigma, Milan, Italy) added in 10\% (v/v) FBS (EuroClone, Milan, Italy), $100 \mathrm{U} / \mathrm{mL}$ penicillin/streptomycin (Sigma-Aldrich, MO, USA), and $2 \mathrm{mM}$ L-glutamine (EuroClone, Milan, Italy) at $37^{\circ} \mathrm{C}$ in $5 \%(v / v) \mathrm{CO}_{2}$. Then, 20,000 cells $/ 50 \mu \mathrm{L}$ were seeded in each well of a 96-well flat-bottom microtiter plate (Sarstedt, Milan, Italy) and incubated overnight at $37{ }^{\circ} \mathrm{C}$ in $5 \% \mathrm{CO}_{2}$. Serial twofold dilutions of D-BMAP18, Pro-D-BMAP18, and Pro-D-BMAP18 in the presence of elastase (molar ratio, 100:1) were prepared in the same cell growth medium, and $50 \mu \mathrm{L}$ of the samples were added to the cells. After $20 \mathrm{~h}$ of incubation at $37^{\circ} \mathrm{C}$ under $5 \%(v / v) \mathrm{CO}_{2}, 20 \mu \mathrm{L}$ of MTT $(5 \mathrm{mg} / \mathrm{mL}$ in PBS) was added to each well. After $4 \mathrm{~h}$ incubation at $37{ }^{\circ} \mathrm{C}$ in the dark, $100 \mu \mathrm{L}$ of $10 \%(w / v)$ Igepal (Sigma-Aldrich, $\mathrm{MO}, \mathrm{USA}$ ) in $0.01 \mathrm{~N} \mathrm{HCl}$ was added to each well and the plate was incubated overnight at $37{ }^{\circ} \mathrm{C}$ under $5 \%(v / v) \mathrm{CO}_{2}$. Cell viability was evaluated as absorbance at $570 \mathrm{~nm}$ using the Nanoquant infinite M200pro multiplate reader (Tecan, Mannedorf, Switzerland).

\subsection{Bacterial Killing Assay in CF Sputum}

Evaluation of antibacterial activity in the sputum of CF patients was measured as bacterial kill assay against the P. aeruginosa strain RP73.

Sputum samples were collected and pooled as already described [25] The pool was then divided into aliquots and frozen at $-20{ }^{\circ} \mathrm{C}$. The assay was performed in $25 \%(v / v)$ sputum in SCFM (synthetic cystic fibrosis sputum medium [22,36]) with the addition of $\mathrm{NaCl}$ to a final concentration of $450 \mathrm{mM}$. Different concentrations of the peptide were mixed with $100 \mu \mathrm{L}$ of diluted sputum for $1 \mathrm{~h}$ at $37^{\circ} \mathrm{C}$ in a thermostatically controlled water bath with $100 \mu \mathrm{L}$ of bacterial cells $\left(10^{6} \mathrm{CFU} / \mathrm{mL}\right)$ resuspended in $25 \%(v / v)$ sputum in SCFM. After incubation, tenfold dilutions of each sample were prepared in $\mathrm{MH}$ broth (Oxoid S.p.A., Milan, Italy) and $25 \mu \mathrm{L}$ of each solution were plated on $\mathrm{MH}$ agar plates (Oxoid S.p.A., Milan, Italy) and incubated overnight for further colony counting.

For C. albicans SC 5314, the assay was performed as described above, but the concentration of fungal cells was approximately $5 \times 10^{4} \mathrm{CFU} / \mathrm{mL}$ and the medium used for dilution and plating was Sabouraud (Sigma-Aldirch, MO, USA) with and without agar, respectively.

In both cases, a plate containing a serial dilution of $25 \%(v / v)$ CF sputum alone without the addition of bacteria/fungi was used as a control for the presence of endogenous bacterial flora. No endogenous bacterial growth was observed in the control plate after incubation due to the different growth speeds of the endogenous strains.

\subsection{Statistical Analysis}

For statistical analysis, data from at least three independent experiments were used, which were internal triplicate experiments. Differences between groups were evaluated using the unpaired Student's $t$-test (biofilm formation) or the ANOVA test (cytotoxicity).

Supplementary Materials: The following supporting information can be downloaded at: https: / / www.mdpi.com/article/10.3390/antibiotics11030319/s1, Figure S1: Proteolytic cleavage of Pro-DBMAP18, Figure S2: Anti-biofilm activity of Pro-D-BMAP18. 


\begin{abstract}
Author Contributions: Conceptualization, M.D., M.M. (Mario Mardirossian) and M.S.; methodology and investigation, M.D., R.S., S.P., M.M. (Mario Mardirossian) and M.M. (Massimo Maschio); data curation, M.D.; writing—original draft preparation, M.D.; writing—review and editing, M.M. (Mario Mardirossian), R.S. and M.S. All authors have read and agreed to the published version of the manuscript.
\end{abstract}

Funding: This research received no external funding.

Institutional Review Board Statement: The study was conducted according to the guidelines of the Declaration of Helsinki and approved by the Institutional Review Board of the IRCCS Burlo Garofolo, project RC n. 362022 "New advances in cystic fibrosis infections".

Informed Consent Statement: Not applicable.

Data Availability Statement: Although not involving any procedure on patients, since the sputum was waste material autonomously expelled by patients and no data on patients were available, informed consent was obtained from all subjects involved in the study.

Acknowledgments: We thank Chiara Agostinis (IRCCS Burlo Garofolo, Trieste, Italy) and Gabriella Zito (IRCCS Burlo Garofolo, Trieste, Italy) for helping in the management of the bureaucratic procedures concerning the approval of the study by the institutional review board.

Conflicts of Interest: The authors declare no conflict of interest.

\title{
References
}

1. Ratjen, F. Cystic fibrosis: Pathogenesis and future treatment strategies. Respir. Care 2009, 54, 595-605. [CrossRef] [PubMed]

2. Steinkamp, G.; Wiedemann, B.; Rietschel, E.; Krahl, A.; Gielen, J.; Bärmeier, H.; Ratjen, F. Prospective evaluation of emerging bacteria in cystic fibrosis. J. Cyst. Fibros. 2005, 4, 41-48. [CrossRef] [PubMed]

3. Høiby, N.; Ciofu, O.; Johansen, H.K.; Song, Z.J.; Moser, C.; Jensen, P.Ø.; Molin, S.; Givskov, M.; Tolker-Nielsen, T.; Bjarnsholt, T. The clinical impact of bacterial biofilms. Int. J. Oral Sci. 2011, 3, 55-65. [CrossRef]

4. Ciofu, O.; Tolker-Nielsen, T.; Jensen, P.Ø.; Wang, H.; Høiby, N. Antimicrobial resistance, respiratory tract infections and role of biofilms in lung infections in cystic fibrosis patients. Adv. Drug Deliv. Rev. 2015, 85, 7-23. [CrossRef]

5. Döring, G.; Conway, S.P.; Heijerman, H.G.M.; Hodson, M.E.; Høiby, N.; Smyth, A.; Touw, D.J. Antibiotic therapy against Pseudomonas aeruginosa in cystic fibrosis: A European consensus. Eur. Respir. J. 2000, 16, 749-767. [CrossRef] [PubMed]

6. Haiko, J.; Saeedi, B.; Bagger, G.; Karpati, F.; Özenci, V. Coexistence of Candida species and bacteria in patients with cystic fibrosis. Eur. J. Clin. Microbiol. Infect. Dis. 2019, 38, 1071-1077. [CrossRef]

7. Hancock, R.E.; Brown, K.L.; Mookherjee, N. Host defence peptides from invertebrates—Emerging antimicrobial strategies. Immunobiology 2006, 211, 315-322. [CrossRef]

8. Mahlapuu, M.; Håkansson, J.; Ringstad, L.; Björn, C. Antimicrobial Peptides: An Emerging Category of Therapeutic Agents. Front. Cell. Infect. Microbiol. 2016, 6, 194. [CrossRef]

9. Kang, S.J.; Park, S.J.; Mishig-Ochir, T.; Lee, B.J. Antimicrobial peptides: Therapeutic potentials. Expert Rev. Anti. Infect. Ther. 2014, 12, 1477-1486. [CrossRef]

10. Datta, S.; Roy, A. Antimicrobial Peptides as Potential Therapeutic Agents: A Review. Int. J. Pept. Res. Ther. 2020, 27, 555-577. [CrossRef]

11. Pasupuleti, M.; Schmidtchen, A.; Malmsten, M. Antimicrobial peptides: Key components of the innate immune system. Crit. Rev. Biotechnol. 2012, 32, 143-171. [CrossRef]

12. Gallo, R.L.; Murakami, M.; Ohtake, T.; Zaiou, M. Biology and clinical relevance of naturally occurring antimicrobial peptides. J. Allergy Clin. Immunol. 2002, 110, 823-831. [CrossRef]

13. Haney, E.F.; Hancock, R.E. Peptide design for antimicrobial and immunomodulatory applications. Biopolymers 2013, 100, 572-583. [CrossRef]

14. Brogden, K. Antimicrobial peptides: Pore formers or metabolic inhibitors in bacteria? Nat. Rev. Microbiol. 2005, 3, 238-250. [CrossRef] [PubMed]

15. Raheem, N.; Straus, S.K. Mechanisms of Action for Antimicrobial Peptides with Antibacterial and Antibiofilm Functions. Font Microbiol. 2019, 10, 2866. [CrossRef] [PubMed]

16. Hollmann, A.; Martinez, M.; Maturana, P.; Semorile, L.C.; Maffia, P.C. Antimicrobial Peptides: Interaction with Model and Biological Membranes and Synergism with Chemical Antibiotics. Font. Chem. 2018, 6, 204. [CrossRef]

17. Zhang, L.; Parente, J.; Harris, S.M.; Woods, D.E.; Hancock, R.E.; Falla, T.J. Antimicrobial Peptide Therapeutics for Cystic Fibrosis Antimicrobial Peptide Therapeutics for Cystic Fibrosis. Society 2005, 49, 2921-2927.

18. Water, V.; Smyth, A. Cystic fibrosis microbiology: Advances in antimicrobial therapy. J. Cyst. Fibros. 2015, 14, 551-560. [CrossRef]

19. Schwab, U.; Gilligan, P.; Jaynes, J.; Henke, D. In Vitro Activities of Designed Antimicrobial Peptides against Multidrug-Resistant Cystic Fibrosis Pathogens. Antimicrob. Agents Chemother. 1999, 43, 1435-1440. [CrossRef] 
20. Forde, É.; Kelly, G.; Sweeney, L.; Fitzgerald-Hughes, D.; MacLoughlin, R.; Devocelle, M. Vibrating Mesh Nebulisation of Pro-Antimicrobial Peptides for Use in Cystic Fibrosis. Pharmaceutics 2019, 11, 239. [CrossRef]

21. Pompilio, A.; Scocchi, M.; Pomponio, S.; Guida, F.; Di Primio, A.; Fiscarelli, E.; Gennaro, R.; Di Bonaventura, G. Antibacterial and anti-biofilm effects of cathelicidin peptides against pathogens isolated from cystic fibrosis patients. Peptides 2011, 32, 1807-1814. [CrossRef] [PubMed]

22. Pompilio, A.; Crocetta, V.; Scocchi, M.; Pomponio, S.; Di Vincenzo, V.; Mardirossian, M.; Gherardi, G.; Fiscarelli, E.; Dicuonzo, G.; Gennaro, R.; et al. Potential novel therapeutic strategies in cystic fibrosis: Antimicrobial and anti-biofilm activity of natural and designed -helical peptides against Staphylococcus aureus, Pseudomonas aeruginosa, and Stenotrophomonas maltophilia. BMC Microbiol. 2012, 12, 1-10. [CrossRef] [PubMed]

23. Skerlavaj, B.; Gennaro, R.; Bagella, L.; Merluzzi, L.; Risso, A.; Zanetti, M. Biological characterization of two novel cathelicidinderived peptides and identification of structural requirements for their antimicrobial and cell lytic activities. J. Biol. Chem. 1996, 271, 28375-28381. [CrossRef]

24. Mardirossian, M.; Pompilio, A.; Crocetta, V.; De Nicola, S.; Guida, F.; Degasperi, M.; Gennaro, R.; Di Bonaventura, G.; Scocchi, M. In Vitro and in vivo evaluation of BMAP-derived peptides for the treatment of cystic fibrosis-related pulmonary infections. Amino Acids 2016, 48, 2253-2260. [CrossRef] [PubMed]

25. Degasperi, M.; Agostinis, C.; Mardirossian, M.; Maschio, M.; Taddio, A.; Bulla, R.; Scocchi, M. The Anti-Pseudomonal Peptide D-BMAP18 Is Active in Cystic Fibrosis Sputum and Displays Anti-Inflammatory In Vitro Activity. Microorganisms 2020, 8, 1407. [CrossRef]

26. Mardirossian, M.; Pompilio, A.; Degasperi, M.; Runti, G.; Pacor, S.; Di Bonaventura, G.; Scocchi, M. D-BMAP18 Antimicrobial Peptide Is Active In vitro, Resists to Pulmonary Proteases but Loses Its Activity in a Murine Model of Pseudomonas aeruginosa Lung Infection. Front. Chem. 2017, 5, 40. [CrossRef]

27. Forde, É.; Humphreys, H.; Greene, C.M.; Fitzgerald-Hughes, D.; Devocelle, M. Potential of host defense peptide prodrugs as neutrophil elastase-dependent anti-infective agents for cystic fibrosis. Antimicrob. Agents Chemother. 2014, 58, 978-985. [CrossRef]

28. Forde, É.; Schütte, A.; Reeves, E.; Greene, C.; Humphreys, H.; Mall, M.; Fitzgerald-Hughes, D.; Devocelle, M. Differential In Vitro and In Vivo Toxicities of Antimicrobial Peptide Prodrugs for Potential Use in Cystic Fibrosis. Antimicrob. Agents Chemother. 2016, 60, 2813-2821. [CrossRef]

29. Scocchi, M.; Skerlavaj, B.; Romeo, D.; Gennaro, R. Proteolytic cleavage by neutrophil elastase converts inactive storage proforms to antibacterial bactenecins. Eur. J. Biochem. 1992, 209, 589-595. [CrossRef]

30. Panyutich, A.; Shi, J.; Boutz, P.L.; Zhao, C.; Ganz, T. Porcine polymorphonuclear leukocytes generate extracellular microbicidal activity by elastase-mediated activation of secreted proprotegrins. Infect. Immun. 1997, 65, 978-985. [CrossRef]

31. Jubeh, B.; Breijyeh, Z.; Karaman, R. Antibacterial Prodrugs to Overcome Bacterial Resistance. Molecules 2020, 25, 1543. [CrossRef] [PubMed]

32. Rautio, J.; Kumpulainen, H.; Heimbach, T.; Oliyai, R.; Oh, D.; Järvinen, T.; Savolainen, J. Prodrugs: Design and clinical applications. Nat. Rev. Drug Discov. 2008, 7, 255-270. [CrossRef] [PubMed]

33. Laval, J.; Ralhan, A.; Hartl, D. Neutrophils in cystic fibrosis. Biol. Chem. 2016, 397, 485-496. [CrossRef]

34. Reeves, E.P.; Molloy, K.; Pohl, K.; McElvaney, N.G. Hypertonic saline in treatment of pulmonary disease in cystic fibrosis. Sci. World J. 2012, 2012, 465230. [CrossRef] [PubMed]

35. Döring, G. The role of neutrophil elastase in chronic inflammation. Am. J. Respir. Crit. Care Med. 1994, 150 Pt 2, S114-S117. [CrossRef]

36. Hancock, R.E.; Sahl, H.G. Antimicrobial and host-defense peptides as new anti-infective therapeutic strategies. Nat. Biotechnol. 2006, 24, 1551-1557. [CrossRef]

37. Chen, C.H.; Lu, T.K. Development and Challenges of Antimicrobial Peptides for Therapeutic Applications. Antibiotics 2020, 9, 24. [CrossRef]

38. Kuipers, B.J.; Gruppen, H. Prediction of Molar Extinction Coefficients of Proteins and Peptides Using UV Absorption of the Constituent Amino Acids at $214 \mathrm{~nm}$ To Enable Quantitative Reverse Phase High-Performance Liquid Chromatography-Mass Spectrometry Analysis. J. Agric. Food Chem. 2007, 55, 5445-5451. [CrossRef] [PubMed]

39. Guo, Y.; Gao, F.; Wang, Q.; Wang, K.; Pan, S.; Pan, Z.; Xu, S.; Li, L.; Zhao, D. Differentiation of HL-60 cells in serum-free hematopoietic cell media enhances the production of neutrophil extracellular traps. Exp. Ther. Med. 2021, 21, 353. [CrossRef] 